\title{
A AFETIVIDADE COMO TRAÇO DA CONSTITUIÇ̃̃O IDENTITÁRIA DOCENTE: O OLHAR DA PSICOLOGIA
} AFFECTIVITY AS AN ASPECT OF TEACHERS' IDENTITY CONSTITUTION: A VIEW FROM PSYCHOLOGY

\author{
Vera Lucia Trevisan de Souza, Ana Paula Petroni e Paula Costa de Andrada
}

Pontificia Universidade Católica de Campinas, Campinas/SP, Brasil

\begin{abstract}
RESUMO
Este trabalho tem o objetivo de investigar os aspectos envolvidos na constituição da identidade docente, em especial o papel da afetividade. A base de nossa investigação é a teoria histórico-cultural, em especial os pressupostos de Vigotski. A coleta de dados foi feita por meio de entrevistas com professores de escolas públicas e privadas do interior de São Paulo. Suas falas estão diretamente ligadas a sentidos atribuídos à vivência docente, e esses sentidos forneceram os dados para a construção e análise do aspecto Afetividade na Escola e sua influência na construção da identidade docente. Ao analisarmos todos os relatos, podemos notar nos professores, em termos de afetividade dentro da escola, a predominância do sentimento de sofrimento, cuja base é a frustração por tantas expectativas e desejos não realizados.
\end{abstract}

Palavras-chave: psicologia histórico-cultural; afetividade; identidade docente; sentidos.

\begin{abstract}
The main objective of this research is to investigate the issues involved in the constitution of teachers' identity, in particular the role of affectivity. The theoretical approach is supported by Historical-cultural psychology, mainly the concepts of Vigotski. Data collection was done through interviews with teachers from public and private schools in Sao Paulo's countryside. Their speeches are linked with senses attributed to the teaching working and these senses provided the data for the construction and analysis of the aspect Affectivity at School and its influence on the construction of teacher's identity. According to the report analysis, we can note the prevalence of feelings of suffering, which is based on frustration of so many hopes and unfulfilled desires.
\end{abstract}

Keywords: historical-cultural psychology; affection; teachers' identity; senses.

Este artigo apresenta parte dos resultados de uma pesquisa maior sobre a identidade docente desenvolvida pelo grupo de pesquisa Processos de Constituição do Sujeito em Práticas Educativas (PROSPED), do Programa de Pós-Graduação em Psicologia da Pontifícia Universidade Católica de Campinas (PUCCamp).

$\mathrm{O}$ interesse em investigar a constituição identitária de professores decorre de nossa experiência no contexto escolar ao observamos que a forma como o professor se representa e se percebe no exercício de sua função, assim como suas concepções de educação, de ensino e aprendizagem interferem sobremaneira em suas práticas pedagógicas. Ao longo do desenvolvimento da pesquisa, no entanto, deparamo-nos com outros aspectos do sujeito que eram proeminentemente representativos de seu modo de conceber a docência e a si próprio como docente: as emoções e os sentimentos emergiam com grande força no movimento de constituição da identidade docente. Os afetos, entendidos como o conjunto das emoções, sentimentos e paixões que constituem o psiquismo humano, tal como o concebe Wallon $(1979,1981)$, também estavam na base dos conflitos que se apresentam na escola, incluindo as relações com as famílias e a comunidade, com a gestão e com o sistema de ensino. Tais fatos nos levaram a aprofundar as análises sobre o que denominamos como aspectos afetivos na constituição da docência, cujos resultados apresentamos neste artigo. 
Assim, como perspectiva teórico-metodológica, partimos dos pressupostos da Psicologia HistóricoCultural que, de acordo com Vigotski ${ }^{1}(1934 / 2005)$, tem, como objeto de estudo, o sujeito histórico cuja constituição decorre do movimento dialético em que, a um só tempo, o sujeito constitui o social e é constituído por ele. Entendido como fenômeno em movimento, o processo histórico evidencia-se como um processo dialético com suas oposições, concordâncias e tensões e produz, via objetivação, uma síntese do fenômeno estudado (Zanella et al., 2007).

A questão da afetividade na teoria de Vigotski tem sido compreendida de maneira controversa pelos autores que a estudam. Alguns consideram que o autor não teria dado a ela uma real importância na constituição do psiquismo humano; outros entendem que a contribuição de Vigotski se restringe aos aspectos cognitivos do desenvolvimento.

Embora não possamos dizer que Vigotski tenha postulado uma Teoria das Emoções, alguns autores reconhecem que ele conferiu grande relevância aos afetos. González-Rey (2009) e Oliveira e Rego (2003), por exemplo, entendem que a perspectiva histórico-cultural aborda as emoções como aspectos constituintes do volitivo-afetivo que está na base do desenvolvimento do psiquismo humano. Já Aguiar e Ozella (2006) e Smolka (1993) entendem que a afetividade na obra de Vigotski pode ser observada nas categorias sentido e significação, utilizadas pelo autor para explicar a singularidade do sujeito.

Já em seu primeiro trabalho publicado no campo da psicologia, Psicologia da Arte (1999), escrito entre 1924 e 1926, como resultado de sua tese de doutorado apresentada em 1925, a questão da afetividade aparece com relevância e está relacionada à apreciação e criação em arte. Mas apenas em 1934, em seu texto intitulado "Pensamento e Palavra", último escrito por ele antes de morrer, o papel da afetividade na constituição do psiquismo aparece com maior clareza e integrado, de maneira indissociável, ao pensamento. Segundo o autor (1934/2005, p.188), para "compreender a fala de outrem não basta entender as suas palavras - temos de compreender o seu pensamento. Mas nem mesmo isso é suficiente também é preciso que conheçamos a sua motivação". Isso porque, para Vigotski, o pensamento é gerado pela motivação, ou seja, pelos desejos e necessidades do sujeito, seus interesses e emoções.

O interesse do autor pela questão das emoções também se evidencia em seu livro Teoría de las Emociones (2004a), escrito entre 1931 e 1933, em que apresenta um estudo histórico psicológico da Teoria das Emoções. Trata-se de um estudo denso, extenso e profundo sobre o que se havia produzido até então sobre o papel das emoções na constituição do psiquismo. Por se tratar de um estudo histórico, Vigotski não chega a propor uma teoria sobre as emoções, mas chega à conclusão de que existe uma polarização na forma de conceber a razão e a emoção, a partir da qual se mantém a fragmentação das dimensões afetivas e cognitivas.

No que concerne à afetividade, a dimensão que Wallon, ao longo de toda a sua obra, confere aos afetos no desenvolvimento do sujeito tem permitido que muitos de seus leitores identifiquem em sua obra uma Teoria das Emoções. De acordo com Galvão (2001) e Mahoney e Almeida (2005), Wallon nos oferece uma Teoria do Desenvolvimento segundo a qual a afetividade assume grande relevância, e as emoções são parte do conjunto afetivo. Wallon (1979) entende a afetividade como a capacidade ou disposição do ser humano de ser afetado pelo meio externo ou interno, por sensações agradáveis ou desagradáveis.

Para Mahoney e Almeida (2005), a afetividade, segundo Wallon, se constitui de emoções, sentimentos e paixões que representariam momentos marcantes, sucessivos e imbricados no desenvolvimento da afetividade. Logo, a afetividade evolui. Esses três aspectos da afetividade - emoções, sentimentos e paixões - resultam de fatores orgânicos e sociais que se configuram de modos diferentes de integração: nas emoções, há o predomínio do fisiológico; no sentimento, do representacional; e, na paixão, do autocontrole (Mahoney \& Almeida, 2005).

A emoção tem um poder plástico, expressivo e contagioso, visto envolver o tônus muscular e se diferenciam pelas oscilações viscerais e musculares e desenvolvem padrões posturais para medo, alegria, raiva, ciúme, tristeza. Já o sentimento seria a expressão representacional da afetividade. Diferentemente da emoção, não resulta em reações imediatas ou diretas, visto elaborar as emoções no âmbito da representação simbólica. A paixão, por sua vez, inaugura o autocontrole como possibilidade de dominar uma situação. Assim, para Wallon (1979), a emoção pode evoluir para sentimento na medida em que pode ser pensada, refletida, compreendida e elaborada via representação. $\mathrm{O}$ autoconhecimento das vivências afetivas permite seu domínio por meio da paixão e equivaleria à possibilidade de conferir sentido às experiências. Para o autor, na constituição do sujeito ao longo de seu desenvolvimento, a afetividade corresponde a um conjunto que se integra aos domínios cognitivo e motor.

$\mathrm{Na}$ escola, observamos o predomínio das emoções e, via de regra, emoções negativas, como 
medo, raiva, decepção, indignação e frustração. Essas emoções, que se expressam de forma explosiva, são geradoras de muitos conflitos que não são trabalhados e arrebatam dos sujeitos a possibilidade de elaborálas. Assim, elas se repetem e constituem um contexto de relações permeado de insatisfações impeditivas do desenvolvimento dos sujeitos. Observamos, também, que a prevalência de emoções negativas acaba por gerar sentimentos que parecem dominar professores e alunos, como a frustração e o desânimo.

\section{Método}

Assumimos, nesta pesquisa, o método dialético que tem, como objeto de estudo, o sujeito histórico. Para Vigotski, "Estudar algo historicamente significa estudá-lo em movimento no seu desenvolvimento histórico. Essa é a exigência fundamental do método dialético" (1927/1995, p. 6). O que o autor quer dizer é que, no estudo de dado fenômeno, ao abranger todas as suas fases e mudanças, desde o momento de seu aparecimento até que deixe de aparecer, o pesquisador "dá visibilidade a sua natureza" $(1927 / 1995$, p. 6) e, desse modo, pode conhecer sua essência, visto que o fenômeno só se mostra quando em movimento.

Outro aspecto fundamental no método proposto por Vigotski é a perspectiva de que se parte para a análise dos processos psicológicos: devemos partir dos mais complexos para se explicar os mais simples. Em suas palavras: "trata-se de mostrar na esfera do problema que nos interessa como se manifesta o grande no pequeno" (1927/1995, p. 64). Ou seja, no estudo que ora propomos, buscamos demonstrar como os afetos presentes nas relações empreendidas pelos professores objetivam a constituição de sua identidade docente, revelada por suas concepções de educação, de aluno e de ensino-aprendizagem. Essa objetivação deve ser entendida, a um só tempo, como expressão e fundamento da condição de exercício da docência. Logo, a análise não pode deixar de considerar as relações entre as partes e o todo, visto que ambos são determinados e se determinam mutuamente: as partes contêm o todo que, por sua vez, é constituído pelas partes.

Foram entrevistados nove professores em exercício nas redes públicas de ensino estadual e municipal e na rede particular de duas cidades do interior e da capital de São Paulo, Brasil. As entrevistas, semiestruturadas, gravadas em áudio e transcritas, com vista no aprofundamento de aspectos observados, foram os principais instrumentos utilizados. Além disso, ocorreram observações nos vários espaços escolares, em especial nas reuniões semanais dos professores (chamadas de Trabalho Docente Coletivo - TDC). Em uma das escolas, as observações ocorreram ao longo de 16 meses, quando se buscou uma maior compreensão do contexto escolar como um todo. Essas observações possibilitaram o desenvolvimento de algumas hipóteses e de novos questionamentos sobre o papel da afetividade na construção da identidade docente.

\section{Procedimento de análise dos dados}

Procedemos à análise dos dados obtidos com base nos pressupostos teórico-metodológicos da Psicologia Histórico-Cultural, privilegiando o levantamento de indicadores sobre o papel da afetividade na constituição da identidade docente. Esses indicadores conduziram à elaboração das seguintes categorias: aceitação e reconhecimento; solidão e abandono; injustiça e revolta; esperança e desejo; e sofrimento.

\section{Discussão e análise dos resultados}

\section{Aceitação e reconhecimento}

Os depoimentos dos professores sobre suas atividades profissionais se revelam permeados de afetos. Em alguns momentos, os afetos que aparecem atrelados aos sentidos atribuídos às suas práticas cotidianas são positivos e parecem se constituir como motivo para se manterem engajados na busca de ações mais efetivas para a promoção da aprendizagem e desenvolvimento de seus alunos, conforme revela a fala da professora $\mathrm{Ana}^{2}$ :

Eu não sei se eu conseguiria trabalhar em outra profissão, voltar a ser uma secretária. Mas, ao mesmo tempo que é muito cansativo, tem alguma coisa, tem um salário invisivel aí, que é importante. ... Em cada sala, sempre tem dois, três, que são ótimos. Você fala assim: "não, para esses aí, valeu a pena ter vindo aqui, arrebentada, porque eles estavam esperando, não faltam, eles querem aprender". Então, é aquele comprometimento moral mesmo. ... Eu descobri que a minha paixão era estar ali dentro [na escola]. Então, foi assim, ao acaso. ... Mas, na escola, a gente lidava com pessoas, o nosso produto eram as pessoas. Então, era muito legal quando a gente conseguia obter um resultado, com alguém que ninguém dava nada para ele e, de repente, você trabalhava, trabalhava, trabalhava e a pessoa desabrochava, se motivava para melhor. Então, era bacana. ... A gente não pode dizer que isso dai é a regra, era a exceção, mas era justamente essa exceção que ficava me puxando para continuar.

Podemos observar como Ana avalia os resultados de suas ações com base nas manifestações 
dos alunos: suas atitudes em sala, o comparecimento e a participação às aulas, e o aprendizado deles. Esses aspectos são compreendidos por ela como dedicação, interesse, respeito e investimento que têm em sua base os afetos. Assim, resultam para ela como um retorno afetivo - os afetos que ela mobiliza no seu trabalho são retribuídos pelos alunos e sustentam seu investimento que permanece - a despeito de seu cansaço e desânimo provocados pela sua condição precária de trabalho. Esse retorno afetivo dos alunos - que para ela equivale ao reconhecimento de seu esforço e investimento - parece se objetivar no que ela chama de "salário invisível".

Na fala da professora Joana, a dimensão do afetivo também assume relevância, ora com afetos positivos, ora negativos, mas ambos com a mesma importância para o modo como vê sua docência:

Às vezes sou chata, tem hora que gostam, me abraçam [imagem que os alunos têm dela], depende da classe. Por exemplo, tem sala que tenho mais de 30 alunos, e alunos que foram encaminhados de outras escolas, porque consideraram que eles tinham déficit de aprendizagem, mas na realidade são super agitados e não conseguem se concentrar. Mas apesar da dificuldade alguns me olham com brilho nos olhos, acho que me veem como uma pessoa importante. Os pais, não sei, nunca participei de reunião com eles, quero que, com o tempo possam me valorizar, por isso, quando é possivel, peço para os alunos levarem trabalho para casa, para eles perguntarem [pais/ responsáveis] quem ajudou vocês a fazer isso?

Fica evidente em sua fala a relevância que os afetos assumem em sua prática: ainda que veja o resultado de seu investimento no brilho dos olhos de alguns alunos - e isso é o que parece motivá-la em suas ações -, há uma queixa velada sobre a falta de participação ou reconhecimento de seu esforço por parte dos pais. Embora declare nunca ter participado de uma reunião, ela espera ser reconhecida mesmo sendo desconhecida e deseja um retorno afetivo sem investir na relação - o que se revela contraditório. Os professores demonstram a necessidade de serem reconhecidos e de terem seu trabalho valorizado em todos os depoimentos e, como veremos mais adiante, a frustração dessa expectativa se revela como um dos motores que promove o desânimo e o descompromisso dos docentes. Vejamos a fala da professora Lourdes: "Você vai dizer que sou egoísta, mas eu gosto muito de massagear o ego... Eu gosto de ver o resultado do meu trabalho. Eu acho que todo mundo gosta, se você não gostar..."

É possível dizer que essa valorização de si a partir do outro surge para o professor como um sinalizador externo de seu trabalho, constituindo um elemento que agrega valor à imagem que ele tem de si, em um processo em que a aceitação assume relevância. Essa aceitação manifestada pelo outro parece constituir-se como motivo para os professores continuarem a investir nos alunos e em sua ação docente.

Vigotski (1934/2005, 1931/2007) descreve a importância do outro como mediador da imagem que o sujeito constrói de si, cuja base é afetiva. $\mathrm{O}$ desenvolvimento humano se dá por meio das relações que só se estabelecem pela mediação dos signos. A palavra e os sinais são representações sociais da realidade vivida pelo sujeito no contato com o outro. As atribuições que o sujeito constrói de si são representadas pelos signos e internalizadas por ele por meio das imagens que os outros lhe atribuem. Trata-se de um processo dialético que envolve uma apropriação individual e singular, a partir do qual o sujeito configura novos sentidos, transformando a si próprio e à realidade (Vigotsky, 1931/2007).

\section{Solidão e abandono}

Outros aspectos afetivos que assumem relevância na expressão dos sujeitos da pesquisa são os sentimentos de solidão e abandono vivenciados pelos docentes na sua prática pedagógica. Ao mesmo tempo em que dizem gostar da profissão e da relação com os alunos, os professores destacam que se sentem desamparados, sem apoio pedagógico ou afetivo para a resolução de problemas que enfrentam, o que, muitas vezes, gera outros sentimentos, como perdição, frustração e impotência. Nas falas, é possível observar que os sentidos atribuídos pelos professores à prática docente correspondem a algo desgastante e solitário:

O único entrave é a falta de o orientador estar junto. Esse elemento da escola, que é uma peça fundamental. Isso é uma das falhas, deveria ter o acompanhamento do meu orientador: o que você planejou? Quais são suas estratégias? Como você vai trabalhar? Esses questionamentos que eu já não tenho aqui, que faltam para poder refletir. Eu acho que o que eu faço está bom, e, às vezes, entra-se no conformismo. Acho que está bom, mas eu tenho que ter o olhar de outra pessoa, isso falta para me ajudar. (Cláudia)

Aprendi bastante como se trabalhar [na escola particular], se organizar e planejar, coisa que na prefeitura, rede pública, não tive esse apoio. ... Eu vejo o lado bom da escola particular por conta disso, de alguém te acompanhar, porque aqui [prefeitura] é muito solto o trabalho. ... Aqui no primeiro ano, são três anos do ciclo, tentando fazer o ciclo acontecer. Duas professoras novas, no primeiro ano, estão perdidas, não tem apoio pedagógico. (Cláudia) 
É, eu acho que isso ai é uma coisa dificil, é uma coisa horrivel, porque você está na sala de aula, você sabe o que acontece, e essas coisas que vêm de lá de cima ... É uma decisão que vem de cima e nós temos que seguir, porque o diretor faz a pressão para que siga aquilo lá e, muitas vezes, não dá certo porque há falta de muitos professores na rede. ... Eu acho certas coisas muito injustas, porque ninguém está lá para ver o que realmente acontece dentro de uma escola... no nosso meio em que vivemos aqui, falar coisas que não tem conhecimento. (Augusto)

Na base da fala da professora Cláudia, é possível identificar um sentimento de insatisfação com seu contexto de trabalho: a escola pública. Ela destaca que a solidão e o abandono vivenciados pelos professores corresponderiam a uma característica específica da escola pública, pois acredita que estava mais amparada quando trabalhava em escola particular. O professor Augusto também caracteriza o trabalho na rede pública pela vivência de situações de solidão e abandono pelos professores, tanto em relação à falta de recursos humanos quanto em relação à pressão de medidas governamentais, de caráter burocrático, que são impostas ao professor e vivenciadas por ele com o sentido de desrespeito, fazendo com que se indigne, ou aja de forma alienada, em que já se naturalizou o fenômeno: não adianta fazer nada, ou o que se pode fazer a não ser acatar?

Por um lado, esse aspecto parece revelar certo descaso e abandono por parte da gestão da escola e, por outro, a impotência do professor ao ter que atender às demandas pedagógicas sem qualquer apoio. A sensação expressa pelos professores é a de que eles precisam conseguir solitariamente exercer seu papel diante dos alunos e, ao mesmo tempo, atender às exigências burocráticas da escola, mesmo que tais exigências não façam qualquer sentido e sejam vividas como injustas, como resultado da falta de conhecimento do sistema de ensino sobre as necessidades reais da escola.

A professora Ana ainda revela um sentimento de mágoa e injustiça quando descreve a imagem negativa que o professor tem diante da sociedade e dos alunos. Esta sensação de trabalho árduo sem reconhecimento e com muitas críticas confere um sentido que podemos interpretar como solidão e abandono, já que o professor demonstra se sentir isolado e criticado perante outros que desconhecem as intempéries de sua atividade profissional.

Você não vê cantor sendo espancado, advogado sendo espancado, mas professor, vira e mexe, aparece um lá. Então, a incidência é muito maior na nossa classe. Mas... existem pessoas que ficam assim... Toda essa negatividade que existe com a nossa profissão, isso interfere: a pessoa fica deprimida, fica revoltada.
Mas o meu compromisso é com o aluno, porque se eu for ficar me preocupando com tudo isso daí: com a direção que faz coisas que eu não gosto; o Orientador Pedagógico que foi embora; a secretária que xingou a gente de incompetente, que a gente está muito bem pago pelo que estamos fazendo; se eu for dar bola para tudo isso daí, então, eu não trabalho mais. $O$ meu objetivo, o meu compromisso, são com os meus alunos. (Ana)

Como podemos observar, os professores sentem-se solitários e abandonados em relação à escola, à sociedade e às políticas públicas. Podemos sugerir que a tarefa de dar conta de tanta demanda dentro e fora de sala de aula faz com que se sintam pressionados e sobrecarregados - do ponto de vista deles, um peso excessivo -, além de terem responsabilidades afetivas que, muitas vezes, não seriam atribuições deles, mas dos pais, da escola ou da comunidade.

O sentido que atribuem à docência é de um trabalho com muitos problemas, em que ele, o professor, enquanto elo mais direto em relação ao aluno, acaba por ser o maior responsável por "sanálos", aspecto este, impossível, pois essas demandas envolvendo alunos em idade escolar são de âmbito sociopolítico, e não pessoal. O professor não consegue dar cabo a tantas exigências - já que nem todas são atribuições suas - e, sendo assim, o sentimento que fica é o de incapacidade para promover resultados positivos por meio de sua ação profissional. Desse modo, sua prática se esvazia de sentidos e provoca desmotivação, descompromisso e, até mesmo, adoecimento. Caberia perguntar: por que o professor toma para si toda a responsabilidade de atendimento às demandas da escola? Por que não envolve a gestão ou os administradores públicos que têm como papel atuar coletivamente nos processos educativos? O que justificaria os sentimentos de abandono e solidão vivenciados pelos professores em uma prática que é, eminentemente, coletiva?

De diversos modos, tem-se dito aos professores que eles são os responsáveis e, por alguma razão, eles têm se apropriado dessas atribuições, ainda que, conscientemente, saibam da impossibilidade de corresponder ao papel que lhes é conferido. É nesse movimento dialético em que se assume a responsabilidade no âmbito do discurso e o descompromisso no âmbito das práticas pedagógicas que novas emoções e sentimentos são gerados. Como regra, sentimentos negativos que se revestem de um caráter individual, mas que são, em essência, coletivos, circulam nas interações que se produzem no interior da escola. 


\section{Injustiça e revolta}

Para Wallon (1979), os atores presentes no contexto de interações do sujeito despertam nele valores e sentimentos que influenciam sua concepção de ser humano. Isso ocorre porque, na visão walloniana, devemos olhar para o sujeito não apenas como alguém isolado no meio do grupo, mas como um "nós" inserido em um grupo segundo uma relação de pertencimento a esse contexto e a partir de um processo de identificação e não-identificação permanente.

Vigotski (1925/2004b, 1931/2007) e Wallon $(1979,1981)$ iluminam nosso pensar sobre como os processos psicológicos são incorporados pelo sujeito a partir das interações e experiências afetivas que ele tem com o contexto em que está inserido: são configurações de sentido resultantes das relações familiares, pedagógicas, culturais, políticas e econômicas. Essa explicação sobre os processos de constituição do sujeito parece responder em parte às nossas indagações, sobretudo àquelas que se referem à razão do sentimento de solidão e abandono expresso pelos docentes. Parece legítimo afirmar que a excessiva exposição a sentimentos negativos em relação à sua ação docente gera os sentimentos de injustiça e revolta, conforme vemos a seguir:

Ele [o familiar] também tem uma parcela de responsabilidade, sim. ... Como todo mundo acha que é a culpa do professor! Todo mundo adora ir lá e botar o dedo e falar que é culpa do professor. Mas ninguém aceita ir lá falar o que ele faz, se vai dar certo ou não. ... Ninguém tem a varinha mágica, como você falou [risos]. Mas eles acham que o professor tem que ter essa varinha mágica! Ele tem que resolver as mazelas da sociedade! Está nas mãos dele. E a gente sabe que não é bem assim. A família e a escola caminham juntas. Não tem que responsabilizar só um. (Kátia)

As regras vêm lá de cima: é assim que vai ser feito... Não questionam se é certo, se é errado, não pedem opinião. Decidem nossa vida. ... Então, é cumprase, faça-se, e não se preocupa em ouvir quem está envolvido para saber se está certo. (Kátia)

Então aquela pessoa [alguém que assume um cargo administrativo] pegou, saiu da sala de aula e ficou, talvez, se formou no magistério e ficou dois ou três anos, se ele ficou, em uma escola; dai ele prestou um concurso ou teve a felicidade de pegar um cargo na diretoria de ensino, foi para lá e de lá ele não saiu e lá ele tem tempo de ficar fazendo, elaborando atividades que queira implantar na escola. Mas muitas dessas atividades não dá, é humanamente impossivel você fazer a aplicação. ... Ah, eu acho certas coisas muito injustas porque ninguém está lá para ver o que realmente acontece dentro de uma escola. Ninguém está lá para ver o momento em que... no meio em que vivemos aqui, falar coisas que não tem conhecimento. (Augusto)

Em outras falas, percebemos que os sentimentos de injustiça e revolta assumem novos contornos. É o caso do processo de vitimização, por exemplo, que se explicaria pelo fato de os professores serem expostos a críticas excessivas e, para manterem-se em sua ação pedagógica, desenvolvem posturas defensivas tais como ocupar o lugar de vítima no processo:

"A turma fala que o professor anda meio estressado... Que não é a toa que os alunos batem em professor... Às vezes, eu também me acho um pouco estressada, mas é por causa da jornada, de alguns alunos indisciplinados" (Kátia).

Ah, então, o problema do professor, eu vou te falar a verdade! Desde quando eu fui fazer o magistério, a culpa é sempre do professor. A mídia veicula notícia. Tudo é sempre culpa do professor! O professor está sempre errado! O professor nunca tem razão. (Kátia)

O professor, ou aparece nos programas educativos, ou ele aparece como vitima de algum aluno, ou ele aparece nos movimentos de greve. E aí a gente vê como o professor é visto como profissional de quinta categoria mesmo, entendeu? Quinta categoria. Porque ele apanha, é tratado como marginal, ele está ali fazendo a sua reivindicação. ... Essa secretária que entrou [refere-se à Secretaria Estadual de Educação], ela diz que o professor ganhava muito bem, que todas as escolas estavam muito bem equipadas e que o professor não sabia dar aula! (Ana)

Podemos pensar que, diante da sensação de abandono, solidão, injustiça e revolta, resta ao professor, impotente, postar-se como vítima de uma situação em que não há culpados, mas sim responsáveis pela proliferação de uma conjuntura crítica da educação brasileira. Nos afetos manifestados pelos sujeitos, é tangível a influência sociopolítica e cultural na constituição da identidade dos professores. Ao analisarmos suas falas, vemos como elas estão permeadas de construções resultantes da influência do contexto. Vigotski (1934/2005) descreve que os sentidos atribuídos a algo são, na verdade, a expressão de um aspecto que vem permeado de manifestações de um sujeito que não está só, mas sim inserido em um processo de experiências histórico-culturais. O que o sujeito é surge como consequência dos processos de significação da realidade social feita por ele em suas trocas sociais. São afetos e volições construídas a partir das experiências vivenciadas com os outros de seu entorno.

Vigotski (1925/2004b) interpreta a psique como um processo de um organismo submerso em constante 
desenvolvimento numa dinâmica de interações com o meio. Sua construção teórico-metodológica prevê a inseparabilidade entre o homem e suas trocas com o contexto em que se insere. Nesse sentido, o ser professor aparece contagiado de concepções aparentemente individuais, mas que, na verdade, são produções originadas por um espelhamento de construções sociopolíticas. Percebemos que essas esferas interferem nos sentidos pessoais dos nossos sujeitos, fazendo com que eles tomem para si configurações que são externas a eles. Aparentemente, esses sujeitos concebem-nas como um constructo interno, mas são construções de sentido resultantes de aspectos macroestruturais sobre os quais os sujeitos parecem não ter consciência.

\section{Esperança e desejo}

Notamos nas falas relatadas anteriormente que os aspectos afetivos assumem relevância nas vivências dos professores. São facetas que revelam carinho pela profissão e pelos alunos, prazer em lecionar, ganhos que transcendem a remuneração financeira. Observamos, também, sentimentos de solidão, de sobrecarga advinda da responsabilidade, de autocobrança e de revolta pela pressão social frente aos fracassos produzidos pelo sistema educacional. Ao mesmo tempo em que se evidenciam indicadores de desprazer pela profissão, paradoxalmente revelamse, em outros momentos, aspectos gratificantes da docência como de extrema importância na vida dos professores. Nas falas a seguir, os sujeitos manifestam certo otimismo quanto ao papel do professor e ao futuro. Aparentemente, haveria nos professores um sentimento de esperança em relação à mudança do cenário em que atuam:

"Eu acho que a gente tem bastante coisa para contribuir, sim. Mas eu queria que eles [alunos] tivessem mesmo uma formação, que fossem mais equilibrados, para que a nossa sociedade ficasse melhor" (Ana).

Então, é a gente ali, incentivando o aluno para não desistir, para seguir em frente. E, realmente, todos que seguiram em frente, hoje, já estão bem melhor. ... É uma profissão em que você interage com outras pessoas, então você aprende muito, também, com a história de vida de cada um. Eu gosto. (Kátia)

Ser professor é algo muito especial, porque você está trabalhando com seres em formação. Então, as crianças não são conclusas. Está trabalhando com a questão da formação da criança, intelectual, social. Eu aprendo muito com as crianças e elas me ensinam, e eu aprendo junto com elas também. É uma profissão super importante, é um desafio constante. (Cláudia)
O que esses relatos suscitam é um questionamento: o que é possível apreender dessas considerações se as confrontarmos com as que apresentamos na categoria anterior? Se tomarmos os depoimentos da perspectiva longitudinal, percebemos claramente uma mistura de sentimentos em relação às ações docentes. Nessa mistura, são experimentados afetos opostos e paradoxais. Sentimentos como esperança e desejo, de natureza positiva, convivem com outros de natureza mais negativa, como injustiça e revolta, em um movimento dialético permanente, constituído e constituinte no e pelo contexto em que atuam os professores. Logo, esse movimento, produzido pela ação docente, produz, ao mesmo tempo, as condições dessa mesma docência. Esse fato permite afirmar que os professores vivem a docência ora como experiência afetiva positiva e ora como negativa.

Vigotski (1931/2007) e Wallon (1981) entendem essa contradição como característica do processo de constituição do sujeito. Para os autores, esse dinamismo dialético, que entendem como em constante movimento, é próprio do ser humano, cujos sentimentos e condutas também se manifestam irregulares, ambíguos: positivos e negativos convivendo em um equilíbrio que ocorre não pela constância de ações, mas pelo dinamismo pendular entre paradoxos.

Para Wallon (1979), afetos, cognição, personalidade e meio se interpenetram, se chocam e, nessa dinâmica de contradições, o sujeito se constitui e se diferencia dos outros de suas relações. Para ele, essa é a própria noção de desenvolvimento. Por isso, na concepção walloniana, o desenvolvimento do sujeito ocorre ao longo de sua vida inteira, desde que haja a diferenciação dinâmica e constante entre sujeito e meio.

Vigotski (1931/2007) também vê a constituição do sujeito abalizada na integração de vários fatores e, sobretudo, dentro de uma perspectiva social. Aborda o sujeito a partir do princípio de que pensamento, cognição, afeto e razão se constituem embasados na gama de experiências sociais e históricas por ele vivenciadas. Ou seja, o comportamento humano está intimamente ligado ao seu ambiente histórico e social, em um processo de mudança permanente, que envolve sempre contradições e não pode ser tomado, portanto, como linear. Logo, compreender a atividade docente dessa perspectiva implica analisála em suas manifestações contraditórias e paradoxais, inseridas em um contexto de produção que impõe aos profissionais determinadas condições materiais de trabalho que são, a um só tempo, produto e condição 
de sua ação. É essa complexidade que temos buscado compreender e, no caso deste artigo, especialmente em relação ao aspecto afetivo das relações escolares.

\section{Sofrimento}

O exame mais profundo dos aspectos que emergem das configurações de sentido de docência pelos professores remete a um afeto que parece aglutinador dos afetos que estão na base dos sentidos que emergem das falas e expressões dos sujeitos investigados: o sofrimento.

Conforme já mencionado, Wallon (1979) atribui grande importância às interações no ambiente educacional, visto considerá-las como fator decisivo no estabelecimento de condições adequadas e promotoras do desenvolvimento. Logo, a afetividade assumiria o papel de fomentadora dos processos pedagógicos. Quando as necessidades afetivas não são satisfeitas, o cognitivo e o motor também são atingidos, pois, tudo está interligado. Ao professor, gera insatisfação e desmotivação, já que, quando o trabalhador motivado se empenha e não vê o retorno de seu trabalho, passa a sentir sua ação como esvaziada de sentido e não há como manter vivos os sentimentos de desejo e esperança. Assim, o docente passa a experimentar uma insatisfação permanente, que acaba por afetar sobremaneira o seu modo de ser e agir, chegando à produção de adoecimento.

\begin{abstract}
De repente eu descobri que estava hipertensa! Mas por que hipertensa?! O único problema que eu vejo é a escola. Não só aqui, lá também [a outra escola em que ela leciona]. Apesar de ser Ensino Médio, tem uma galera, também, que quer ficar ouvindo música o tempo todo... E você quer fazer um trabalho bacana, então, você entra em choque. Eu quero ensinar, passar alguma coisa, quero que eles aproveitem esse tempo que estão aqui. Daqui a pouco, muitos já estão trabalhando, daqui a pouco namoram, casam. E ai, como é que ficam as vidas dessas pessoas? (Ana)
\end{abstract}

O fato é que a gente não está conseguindo. Isso é muito frustrante. Eu sempre falo assim: "eu não conheço nenhum profissional que briga para trabalhar.". Porque, veja, se você tiver em uma repartição pública ... em serviço administrativo, e seu chefe, ou alguém, estiver tirando o computador da sua mão, sei lá, o livro da sua mão, e você fala: "se você não quiser que eu trabalho, eu vou ficar em casa”; vai achar ótimo. A gente não! A gente está constantemente brigando com eles, o tempo todo, a gente se desgasta, a gente se arrebenta, para poder trabalhar, entendeu? (Ana)

"Porque, se você levar muito ali, você fica muito nervosa! Por isso que muita gente pede licença, entendeu? Porque não aguenta" (Kátia).
Haveria, por parte dos sujeitos, uma capacidade de olhar para as próprias práticas, mas também de sofrer por perceber que suas expectativas não se consolidaram. Os professores manifestam preocupação em relação ao próprio trabalho, deixando transparecer o sentimento de frustração:

"Às vezes, saio frustrada porque aquilo não deu certo, de falar: 'poxa, tenho que pensar em outra estratégia porque não funcionou'. Então, são sinais para eu poder pensar". (Cláudia)

Ai é onde passa o questionamento: "essa atividade deu certo, ótimo. Aí, não deu certo"; aí você fica frustrada. Então, fala: "nossa, e agora?! Como eu vou trabalhar isso? ... [Falta] Apoio, da direção, motivação, porque, você faz um monte de atividades, legal, prepara um monte de coisa, pensando no aluno, o que é bom para o aluno. E, muitas vezes, você se frustra e ai complica. (Kátia)

Trabalhar na rede pública é assim: a gente trabalha de acordo com a administração. Cada vez que muda o prefeito, vem mudança, e, às vezes, é alguma coisa que estava dando certo, que a gente se empolgou, achou que esse era o caminho, dai desmorona tudo, começa tudo de novo. Isso é terrivel. ... E a gente percebe que o fracasso, às vezes, da educação pública, está muito ligado a essa questão. (Ana)

Wallon (1979) destaca a escola como um meio importante para a constituição do sujeito.Assim, a escola surge como um dos principais ambientes constituintes do sujeito, em termos sociais, afetivos e cognitivos. Para o autor, a escola é como uma promotora ideal do desenvolvimento e deveria estimular os vínculos de cooperação, o trabalho em equipe e o espírito de solidariedade, ao invés de destacar o preconceito, a rivalidade, a pressão e as individualidades. Mas o que vemos nas falas dos sujeitos é justamente o contrário: a questão do sofrimento aparece fortemente como constituinte do dia a dia de sua prática. Mais especificamente, o que predomina é a frustração por haver tantos afetos não correspondidos. Existe desejo de aceitação e reconhecimento, necessidade de estabelecimento de vínculos e inúmeros desejos frustrados pelas condições da realidade educacional e sociopolítica.

Há esperança e muitas intenções sinceras de se fazer um bom trabalho, mas esbarram nas determinações administrativas, nas rixas de dentro da escola e na própria limitação do aluno e do professor. Esses aspectos, somados às inúmeras pressões que rodeiam os docentes, geram sentimentos de solidão e abandono, injustiça e revolta. 
O que vemos nos sentidos e significados da prática docente é que um desgosto é relatado com diversas topologias, dentre as quais a frustração parece estar na base de todas as representações afetivas de sofrimento ligadas à prática docente. Notamos que aquilo que desejam, necessitam, sonham e acham justo para si, para os alunos e para a educação soa um pouco utópico para a realidade brasileira com seus trâmites administrativos e políticos e para os déficits sociais e econômicos. Os professores estão conscientes de que há uma grande lacuna entre o que deveria ser feito e o que pode ser feito. Isso desperta, em todos os sujeitos, o sentimento de frustração, seja na forma de revolta, vitimização, solidão, desejo e esperança ou de necessidades (frustradas) de reconhecimento, vinculação ou, mesmo, aceitação.

Disso, irrompe uma questão: como esse sofrimento se reflete e qual o seu peso na constituição da identidade docente? O que percebemos é que o professor toma para si toda a responsabilidade pela educação dos alunos e não menciona a responsabilidade da escola como facilitadora da prática docente e dos processos de ensino e aprendizagem. Também não demonstra conhecer ou refletir sobre os aspectos macrossociais da educação, que são de natureza política, econômica e social. Logo, por razões que merecem ser investigadas, o professor assume um compromisso que deveria ser distribuído entre o coletivo da escola (diretores, coordenadores), os pais, a sociedade e os poderes públicos (municipal, estadual e federal). Seria esse um dos aspectos que confere o sentido de solidão e sofrimento à prática docente? Embora todos sejam produzidos social e culturalmente, por que o professor os toma para si?

Inferimos que, quando o professor não vê reconhecido o resultado de seu trabalho ou quando é considerado incompetente, emerge disso o sentimento de solidão pela falta de troca, apoio e reconhecimento. Ele se torna, então, um trabalhador alienado, que tem seu fazer esvaziado pela falta de sentido decorrente da impossibilidade de acessar, tomar o produto de sua ação e de seu trabalho. Esses fatores acabam gerando o que chamamos de condição de sofrimento. Assim, é possível afirmar que o contexto em que o docente se insere gera uma condição que sustenta uma representação do professor como sofredor. Tal representação se constitui como uma das razões do imobilismo encontrado na escola, o qual impede os professores de enfrentarem as condições adversas que vivenciam e de empreenderem-se em processos de mudança.

\section{Algumas considerações finais}

A análise dos dados da pesquisa e as reflexões que empreendemos ao longo de seu processo nos permitem afirmar que a afetividade está na base da constituição da identidade no trabalho. E, no caso do trabalho desenvolvido na escola, a afetividade, caracterizada como espaço de práticas sociais coletivas, assume ainda maior relevância por constituir-se concomitantemente à volição e compor a base de toda conduta ou pensamento, tal como afirma Vigotski (1934/2005). Logo, o ato de representar-se a si próprio como docente tem como motivação os afetos vivenciados neste papel, o qual, por ser configurado de formas diversas pelos atores que exercem essa função, compõe diferentes personagens. Esse processo de constituir-se como professora Kátia, ou professora Cláudia, ou professor Augusto, evidenciando diferentes personagens, decorre da forma como cada um configura os significados e sentidos da docência. Essa configuração toma como base a história e a experiência de cada um em relação às suas vidas pessoais e profissionais e diz respeito aos modos de subjetivação da ação de ensinar e aos modos de expressão desse mesmo ensino, ambos os quais envolvem, necessariamente, sua identidade como professor.

Ao analisarmos todos os relatos, podemos notar que os professores conferem um destaque ao estabelecimento de vínculo e às construções afetivas dentro da escola. Eles buscam este tipo de vivência no ambiente pedagógico, mas parecem perdidos, sem saber o que fazer com os seus afetos e com os de seus alunos. Os professores não têm consciência de que os afetos possam se constituir como facilitadores de sua prática docente, assim como não entendem que devem, como tarefa, intervir nas relações afetivas. Entendem que sua função é trabalhar para o desenvolvimento cognitivo, como se o aprendizado não envolvesse todos os aspectos constituintes do sujeito: o cognitivo, o afetivo, o biológico e o social.

Evidenciou-se também na pesquisa a emergência de vários afetos contraditórios em relação ao ambiente escolar e a seus sujeitos. Sentimentos bons e ruins se misturam e se confundem: ora os professores se sentem aceitos e reconhecidos, ora sofrem e se frustram ao não receberem retorno de seu trabalho. Ao mesmo tempo em que se mostram esperançosos quanto ao resultado de sua atuação e a um futuro melhor para seus alunos, manifestam também sentimentos de mágoa e ressentimento voltados à coordenação da escola, às políticas públicas e, até mesmo, à sociedade. Sentemse julgados e condenados sem direito à defesa, como 
se fossem os únicos responsáveis pelo desempenho escolar das crianças e dos adolescentes.

A necessidade de ver seu trabalho reconhecido é, ao mesmo tempo, impulsionadora para a carreira docente e frustrante quando o professor não se vê valorizado. $\mathrm{O}$ reconhecimento do outro, ou a sua falta, resulta em sentimentos de revolta, de injustiça e em vitimização. A frustração que vivenciam é de tal ordem que os mantém presos, solitários e abandonados à própria sorte.

Concluímos através deste estudo sobre a afetividade na escola que a consciência da relevância de seu papel de professor no âmbito da educação escolar aparece muito claramente nas falas dos sujeitos. Porém, o que predomina em termos de afetividade é o sofrimento que decorre da frustração por tantas expectativas e desejos não realizados. Romper a representação de sofrimento e de trabalho inferior é o desafio que se apresenta, se o que se busca é uma constituição de identidade da docência como trabalho digno e de uma maior relevância para o desenvolvimento dos jovens em idade escolar. Enfrentar esse desafio é o caminho para a conquista de ações realmente transformadoras.

Resta-nos chamar a atenção para a necessidade premente de se fomentar a criação de espaços para a elaboração das questões afetivas na escola, não só dos docentes, mas também dos alunos. Destacamos o papel do psicólogo escolar que, longe de "resolver problemas de aprendizado e de conduta", estereótipo maior dessa função, deveria atuar no sentido de assegurar, de forma preventiva, a prevalência de momentos em que tanto professores quanto alunos pudessem manifestar toda essa gama de emoções e sentimentos, obter escuta para suas expressões e poder, assim, elaborar tudo isso através de um processo de conscientização sobre aquilo que vive e por que vive de uma determinada forma. É importante que esses momentos possam ser proporcionados como rotas de expressão de suas dificuldades escolares, afetivas e sociais, de modo a configurar novos significados e sentidos para suas vivências e a avançar em seus processos de constituição identitária de alunos-sujeitos-cidadãos e de professores-sujeitos-cidadãos.

\section{Notas}

1 Optamos por padronizar, neste texto, a grafia do nome do autor como Vigostki. Em chamadas de citações entre parênteses e nas referências, entretanto, será mantida a escolha do tradutor.

2 Os nomes utilizados são fictícios.

\section{Referências}

Aguiar, W. \& Ozella, S. (2006). Núcleos de significação como instrumento para a apreensão da constituição dos sentidos. Psicologia: Ciência e Profissão, 1(1), 222-245.

Galvão, I. (2001). Henri Wallon: uma concepção dialética do desenvolvimento infantil. Petrópolis, RJ: Vozes.

González-Rey, F. L. (2009). La significación de Vygotski para la consideración de lo afectivo en la educación: las bases para la cuestión de la subjetividad. Actualidades investigativas en Educación, 9, 1-24.

Mahoney, A. A. \& Almeida, L. R. (2005). Afetividade e processo ensino-aprendizagem: contribuições de Henri Wallon. Psicologia da Educação, 20, 11-30.

Oliveira, M. K. \& Rego, T. C. (2003). Vygotsky e as complexas relações entre cognição e afeto. In V. A. Arantes (Org.), Afetividade na escola: alternativas teóricas e práticas (pp. 13-34). São Paulo: Summus.

Smolka, A. L. B. (1993). Construção de conhecimento e produção de sentido: Significação e processos dialógicos. Temas em Psicologia, 1(1), 7-15.

Vigotski, L. S. (1995). Obras Escogidas III - Problemas del desarrollo de la psique. Madrid: Visor Distribuciones. (Original publicado em 1927)

Vygotsky, L. S. (1999). Psicologia da Arte (P. Bezerra, Trad.). São Paulo: Martins Fontes. (Original publicado em 1925).

Vigotski, L. S. (2004a). Teoría de las emociones. Madrid: Ediciones Akal. (Original publicado em 1933)

Vygotsky, L. S. (2004b). Teoria e método em Psicologia (C. Berliner, Trad., $3^{\mathrm{a}}$ ed.). São Paulo: Martins Fontes. (Original publicado em 1925)

Vygotsky, L. S. (2005). Pensamento e palavra. In L. S. Vygostky, Pensamento e linguagem (J. L. Camargo, Trad., J. Cipolla Neto, Rev. Técn., $3^{\mathrm{a}}$ ed., pp. 149-190). São Paulo: Martins Fontes. (Original publicado em 1934)

Vigotsky, L. S. (2007). A formação social da mente: o desenvolvimento dos processos psicológicos superiores (M. Cole et al., Orgs., J. Cipolla Neto, L. S. Menna Barreto, \& S. C. Afeche, Trads., $7^{\mathrm{a}}$ ed.). São Paulo: Martins Fontes. (Original publicado em 1931)

Wallon, H. (1979). A Psicologia e educação da criança. Lisboa: Veja Editora.

Wallon, H. (1981). As origens do caráter na criança. Lisboa: Editoria 70.

Zanella, A. V., Reis, A. C., Titon, A. P., Urnau, L. C., \& Dassoler, T. R. (2007). Questões de método em textos de Vygotski: contribuições à pesquisa em psicologia. Psicologia \& Sociedade, 19(2), 25-33.

Recebido em: 13/08/2010

Revisão em: 18/10/2010

Aceite em: 17/11/2010

Vera Lucia Trevisan de Souza é Professora Doutora e Coordenadora do Programa de Pós-Graduação Stricto Sensu em Psicologia como Profissão e Ciência da Pontifícia Universidade Católica de Campinas (PUCCamp). Endereço: Laboratório de Pós-graduação em Psicologia - PUCCamp. Avenida John Boyd Dunlop, 
s/no. Jardim Ipaussurama. Caixa-Postal: 317. Campinas/SP, Brasil. CEP 13059-900. Email: vera.trevisan@uol.com.br

Ana Paula Petroni é psicóloga escolar, Mestre e Doutora (Bolsista CAPES) em Psicologia pelo Programa de PósGraduação Stricto Sensu em Psicologia como Profissão e Ciência da Pontifícia Universidade Católica de Campinas (PUCCamp).. Endereço: Rua: Ernesto Meneghetti, 46, Jardim Santa Marta. Araras/SP, Brasil. CEP 13607-160 Email: anappetroni@gmail.com

Paula Costa de Andrada é Mestre (Bolsista CAPES) e Doutoranda (Bolsista CNPQ) do Programa de PósGraduação Stricto Sensu em Psicologia como Profissão e Ciência da Pontifícia Universidade Católica de Campinas (PUCCamp) e especialização pelo Instituto de Psicologia da USP. Endereço: Estrada Soberana, 203, Chácaras Interlagos. Atibaia/SP, Brasil. CEP 12941-195. Email: p.andrada@uol.com.br

\section{Como citar:}

Souza, V. L. T., Petroni, A. P., \& Andrada, P. C. (2013). A afetividade como traço da constituição identitária docente: o olhar da psicologia. Psicologia \& Sociedade, 25(3), 527-537. 